\title{
The interplay between DNA methylation, folate and neurocognitive development
}

DNA methylation provides an attractive possible means for propagating the effects of environmental inputs during fetal life and impacting subsequent adult mental health, which is leading to increasing collaboration between molecular biologists, nutritionists and psychiatrists. An area of interest is the potential role of folate, not just in neural tube closure in early pregnancy, but in later major neurodevelopmental events, with consequences for later sociocognitive maturation. Here, we set the scene for recent discoveries by reviewing the major events of neural development during fetal life, with an emphasis on tissues and structures where dynamic methylation changes are known to occur. Following this, we give an indication of some of the major classes of genes targeted by methylation and important for neurological and behavioral development. Finally, we highlight some cognitive disorders where methylation changes are implicated as playing an important role.

First draft submitted: 6 January 2016; Accepted for publication: 20 March 2016; Published online: 20 June 2016

Keywords: 5-hydroxymethylation • Barker hypothesis $\bullet$ DNMT1 $\bullet$ DNMT3A • homocysteine - MeCP2 • TET

Recent research has led to the unexpected insight that the cells in the brain have greater plasticity with respect to DNA methylation than had previously been suspected. Due to the replicative quiescence of neurons, and the dogma that methylation could only be lost passively through dilution following cell doubling, it was thought that few changes could occur after differentiation. While this seemed at odds with the high levels of methyltransferases seen in the brain, it was only with the discovery of 5-hydroxymethylation $(5 \mathrm{hmC})$ in the neurons of the CNS $[1,2]$ that a possible mechanism for dynamic change and adaptation could be seen. Moreover, recent identification of prevalent non-CG methylation ( $\mathrm{CpH}$ methylation) existing in neurons has sparked further interest into epigenetic regulation of the brain [3]. Coupled with an influential proposal about the possible developmental origins of adult disease $[4,5]$ this has led to an explosion of research at the interface between neurodevelopment, epigenetics and psychiatry.

The Barker hypothesis outlines how childhood nutritional states may influence adulthood disease [6]. One major source of environmental epigenetic change during development is thought to be maternal nutrition, based both on studies in model organisms and from longitudinal cohorts such as the Dutch Winter Famine survivors [5,7]. While such extreme conditions are not the norm, a more common source of variation in diet is due to insufficient provision of folate, which is recommended to all mothers-to-be to cover the increased requirements for this vitamin during pregnancy [8]. Notably, it is well established that suboptimal folate status during the first trimester greatly increases the risk of neural tube defects (NTDs) with consequent severe effects on brain development. Less clear
Epigenomics

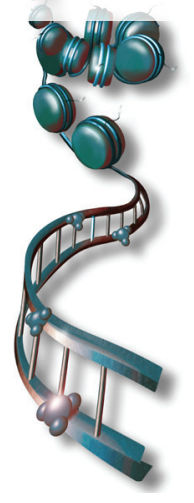

Rachelle E Irwin', Kristina Pentieva', Tony Cassidy², Diane J Lees-Murdock', Marian McLaughlin², Girijesh Prasad $^{3}$, Helene McNulty ${ }^{1}$ \& Colum P Walsh*,1

'EpiFASSTT study, Biomedical Sciences, Ulster University, Coleraine, UK EpiFASSTT study, Psychology, Ulster University, Coleraine, UK ${ }^{3}$ EpiFASSTT study, Computer Sciences Research Institutes, Ulster University, Londonderry, UK

*Author for correspondence:

cp.walsh@ulster.ac.uk

Future
Medicine
part of 
are the potential effects of low maternal folate status in the later stages of fetal development, and how these may impact on the major epigenetic changes which are ongoing in the developing brain. Here, we collate data from diverse sources to give an overview of the major events in human fetal brain development, including structural changes, methylation dynamics and the effects of deficiencies in methyl addition or removal. In addition we survey some of the candidate neuronal gene targets regulated by methylation as well as listing some of the neurological disorders where these genes may be involved. We conclude by looking at possible future studies involving longitudinal cohorts utilizing the latest molecular techniques and what these may tell us.

\section{Folate \& DNA methylation}

Folate (referred to as folic acid in its synthetic form as provided in dietary supplements or fortified food), is a water-soluble B-vitamin essential for viable embryonic development and remains an important dietary constituent throughout life. Biologically, folate is required for one-carbon metabolism involving the transfer and utilization of one-carbon units in essential pathways. The human body cannot synthesize folate de novo and thus two critical pathways are dependent upon sufficient dietary intake as a one-carbon source: DNA synthesis [9] and the DNA methylation cycle, reviewed in Kirkbride et al. [10]. The former is likely to be particularly important in early pregnancy when growth is most rapid as it is essential for cell division and tissue growth. The latter may be more important in later stages of neural development when genomewide remodeling of DNA methylation is seen to occur, as we will describe below. DNA methylation requires S-adenosylmethionine (SAM) as a universal one carbon donor, which is obtained from the methyl groups derived from folate.

DNA methylation patterns are established during embryonic development and the methylation profile of the embryo is dynamically changed throughout lineage specification and differentiation. Folate is a limiting factor in the methylation cycle, and thus suboptimal intake of this essential nutrient in utero may alter the epigenetic marks of essential genes, such as those implicated in neural development that are targeted by DNA methylation. These modifications may lead to sustainable functional alterations throughout the lifetime, potentially predisposing the developing individual to neurological disorders. However, the impact of folate availability in utero on neural DNA methylation patterns and the effects on brain function are at present poorly characterized. Embryonic exposure to nutrients in utero is predominantly maternally controlled, thus alteration of the maternal diet may directly affect the epigenome of the developing individual with later life consequences.

\section{Proven role of folic acid supplementation in preventing NTDs}

\section{Brief timeline}

Conclusive evidence from humans has existed for nearly 25 years that folic acid supplementation of mothers in early pregnancy protects against NTDs, although the precise mechanism to explain this effect has not been fully elucidated. NTDs are congenital malformations of brain or spine where the neural tube fails to close early in development (see Figure 1A \& B), leading to later conditions such as anencephaly and spina bifida [11]. These malformations arise around the third week of pregnancy, approximately 21-28 days post-conception, and this is often a period when women do not realize they are pregnant [12]. During this critical window of development, rapid cell division occurs allowing neural tube closure and growth of the placenta, and adequate folate intake is required, as it is estimated that during pregnancy, maternal folate concentrations fall to $50 \%$ of non-pregnant concentrations [8]. Prior to the mandatory fortification of food with folic acid in the US, NTDs were estimated to occur at 1 in every 1000 pregnancies [13]. Over 30 years ago, formative work demonstrated that women who had given birth to a child with a NTD were deficient in several micronutrients, most significantly folate [14]. Randomized control trials demonstrated that women supplementing their diet with folic acid periconceptionally had a threefold reduction in first occurrence and reoccurrence NTD risk [13,15]. This prompted the recommendation by the US Public Health Service for all women of childbearing age to consume $400 \mu \mathrm{g}$ of folic acid/day [16]. However, since only $30 \%$ of women who became pregnant cohered to these guidelines, and given the fact that approximately half of all pregnancies are unplanned [17], the US FDA implemented legislation mandating fortification of all grain products. The prevalence of NTDs in the USA has since decreased by $30 \%$, and several countries worldwide have adopted this pre-emptive strategy [18].

\section{Gaps in the current knowledge Mechanism by which folic acid prevents NTDs}

The role of folic acid in NTD risk-reduction is wellsupported; however, the underlying mechanistic basis of this effect is much less clear and is likely to be multilayered and complex, due to the biological versatility of this micronutrient. Folic acid is converted to 5,10-methylenetetrahydrofolate (5,10-methlyTHF) and then further metabolized by the MTHFR enzyme to create 5-methyltetrahydrofolate (5-MeTHF), the circulating 
form of folate required for methionine creation needed for methyl group synthesis. Polymorphisms in MTHFR, particularly the $\mathrm{C} 677 \mathrm{~T}$ polymorphism, have been associated with an increased risk of NTDs [21]. 5-MeTHF is taken up into cells via folate receptors FOLR1 and FOLR2, loss of which results in early embryonic lethality [22]. FOLR1 deficient mice develop NTDs, however, they can be rescued by folic acid supplementation, highlighting the crucial role for folate uptake during embryonic development $[22,23]$. Within the cell folate is required as a cofactor for folate-mediated one-carbon metabolism, essential for DNA synthesis, interruption of which could prevent proper closure of the neural tube. In order to facilitate rapid DNA replication of the developing neural tube, a large pool of nucleotides is required for DNA synthesis, for example in neuroepithelial cells. Inadequate supply of nucleotides to these cells halts cellular replication and proper development of the neural folds [24], a theory supported by a variety of mouse models. Splotch mouse models of spina bifida demonstrated a deficiency of deoxythymidine monophosphate biosynthesis, which could be rescued by folic acid supplementation [25]. Consequently, in these mice folate deficiency affected neural stem cell (NSC) differentiation into neurospheres, proliferation and junction formation. In another informative mouse model, knockout of SHMT1, encoding the enzyme required for repartition of carbon units between thymidylate biosynthesis and homocysteine remethylation, resulted in anencephaly when exposed to folate deficiency in utero [26,27]. Finally, knockout of MTHFD1, a gene required for purine biosynthesis, resulted in abnormal neural tube closure and premature death around embryonic day 10.5 (e10.5) [28]. In human, SNPs existing within the promoter region of MTHFD1, have been associated with increased NTD risk [29].

While its role in DNA biosynthesis may be more crucial at this early stage given the rapid growth of the embryo, it is also possible methylation may play a role during early gestation too [30]. As mentioned above, folate is required to generate SAM, the universal methyl donor required for methylation of DNA, RNA and proteins. Folate deficiency has been associated with NTDs through decrease in methyl donor availability; however, the exact underlying mechanisms remain to be fully elucidated. Dunlevy et al. exposed mouse embryos to 5-azacytidine, a methyltransferase inhibitor, during the cranial neurulation period [31]. Interestingly, decreasing DNA methylation specifically increased NTD prevalence, affected the expression of numerous genes essential for cranial neurulation and also affected methylation of cytoskeleton proteins known to become methylated at the stage of neural tube closure such as tubulin and $\beta$-actin [31,32]. Exposing chick embryos to a combination of methylation cycle inhibitors [33] also resulted in delays in neural tube closure. Mice with homozygous mutations in the DNMT3B gene, encoding one of the major enzymes responsible for methylating DNA, also resulted in distortion of the neural tube, highlighting the importance of DNA methylation during rapid growth periods [34]. Findings in clinical human NTD case subjects also showed that affected individuals had significantly lower global methylation levels in neural tissues and thus an impaired methylation pattern [35]. Similarly, Chang et al. revealed that $5 \mathrm{mC}$ levels in the brain of a NTD fetus was decreased relative to other tissues, suggesting that folate is particularly necessary for brain development [36]. There are also a number of links between folate, methylation and schizophrenia, expertly reviewed in [10].

\section{Benefits or not of folic acid in later brain development}

Although maternal folic acid supplementation has been deemed as an essential protective measure against NTDs, and women are recommended to take $400 \mu \mathrm{g} / \mathrm{d}$ folic acid periconceptionally and until the end of the first trimester, clinical recommendations as to whether or not pregnant women should continue this supplementation during the final two trimesters remains unresolved. Continued supplementation has been shown to be effective in increasing both maternal and cord blood folate status [37]; however, the effects of this increase on mother and baby remains to be elucidated fully.

Not only does folate restriction affect neural tube closure, but folate and related B-vitamins are thought to be fundamental in regulating later neurodevelopment [37-39]. However, evidence in the literature is sparse with regard to the effects on specific areas of brain function, such as cognition, motor skills and memory [40] with the majority of evidence existing from observational and animal studies. With the known role of folate in DNA nucleotide biosynthesis, perhaps unsurprisingly several animal studies have shown that folate deficiency can affect brain structure during development, with a reduction in neural cell proliferation, differentiation, survival and neuronal plasticity $[40,41]$. For example, particular brain areas such as the cerebellum, striatum and hippocampus have been shown in rats to undergo apoptosis due to accumulation of homocysteine resulting from folate deficiency [42]. In the same system, folate deficiency resulted in a reduction in neuronal progenitor cell (NPC) numbers in the fetal cortex [43]. Given the known role of folate in methylation, single-base 


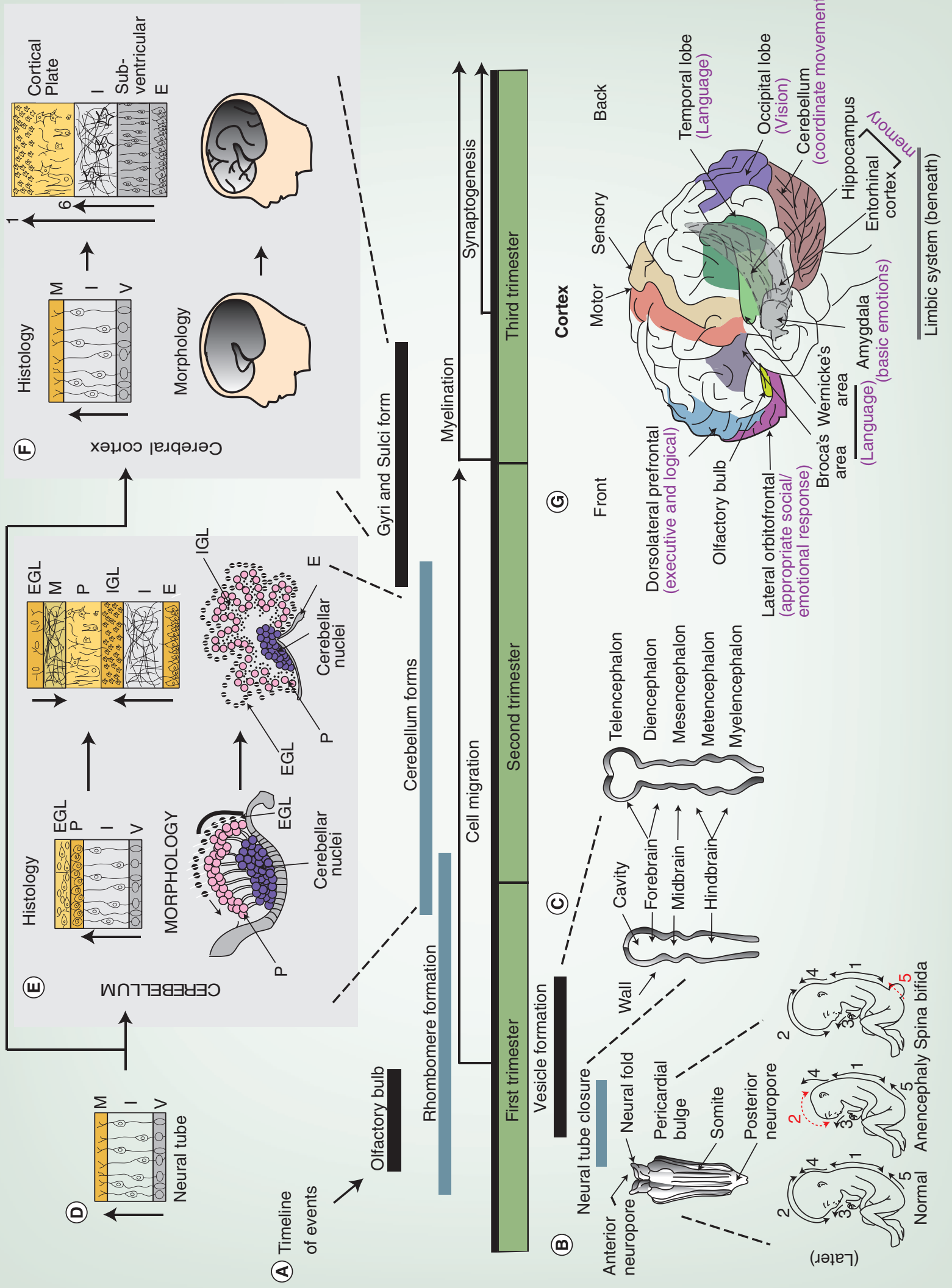


Figure 1. Relevant milestones in human brain development (see facing page). (A) Timeline of brain development (center) indicating periods (shaded boxes above and below line) when some of the structures discussed in the review are formed as well as when major cellular movements or differentiation events occur (bent arrows).

(B) Closure of the neural tube at embryonic day 21-28. The neural folds close over by region (numbered 1-5):

failure to close off the region in red will, much later in development, lead to the indicated neural tube defect. (C) Primary vesicle formation commences around the 4th week of gestation, generating the fore-, mid-and hind-brain regions. (D) Histogenesis of the neural tube. Neural progenitor cells undergo mass self-replication prior to migration and differentiation into non-mitotic neurons by the second trimester. Neural progenitor cells with proliferative capacity remain on the $\mathrm{V}$ of the neural tube, but differentiated non-mitotic daughter cells migrate outwards (denoted by arrow) along glial processes in the I to form a M distal to the vesicle. (E) Formation of the cerebellum occurs largely in the second semester via a unique morphogenetic event, evaginating from the underlying ependymal tissue. Migration of EGL cells across the surface of the tissue (arrowed at bottom), gives rise to a second distal layer of proliferative cells distal to the vesicle, which produces differentiated cells of the marginal zone. Inside a layer of differentiated and highly-branched $P$, neurons migrating outwards from the vesicular side (now called the E) form a second, IGL. (F) In the cerebral cortex migration outwards of the differentiated neurons occurs in waves, traveling successively shorter distances, giving rise to the six layers of the cortical plate. Externally (below), this causes the initially smooth surface of the cortex to become more invaginated and folded into a characteristic pattern of gyri and sulci. (G) Maturation of the cortex entails demarcation of regions associated with higher cognitive functions such as language (e.g., Broca's and Wernicke's areas) and social interaction (orbitofrontal). Components of the limbic system underneath (dashed lines) also play important roles in sociocognitive functioning.

E: Ependymal layer; EGL: External granular layer; I: Intermediate zone; IGL: Internal granular layer; M: Marginal layer; P: Purkinje cells; V: Ventricular side.

Elements redrawn with permission from $[19,20]$.

resolution brain methylome maps were generated from offspring exposed to continued folic acid supplementation throughout gestation and these showed alterations to key developmental genes, including imprinted genes, and altered gene expression profiles [44].

The majority of studies in human have shown a positive correlation between folic acid supplementation during the first trimester and brain function, particularly in motor development, verbal and cognitive performance [45-49]. The CNS is most vulnerable to environmental influence, such as nutrition, when its state of change and plasticity is at its greatest [38]. In human gestation, the period of rapid growth and development of the fetal brain occurs between weeks 24-42 of gestation (i.e., the second and third trimester) [19]. This 'brain spurt' period is particularly plastic and is when neuronal proliferation, differentiation and myelination occurs [50]. It is believed therefore that suboptimal folate status during this period would have a greater effect on neurodevelopment and indeed this has been confirmed in observational studies [46,51]. A small randomized control trial showed that children prenatally exposed to folic acid supplementation in the second and third trimester scored significantly higher in the cognitive domain of the Bayley's development assessment than those children whose mothers only took supplementation during the first trimester [52]. In a larger Mexican cohort, a country with a high incidence of the MTHFR C677T polymorphism, revealed that solely mothers who were homozygous for the TT alleles and also had a low intake $(<400 \mathrm{mg} /$ day $)$ of folic acid during pregnancy birthed children with a reduced mental development index as scored also by the Bayley's development assessment [53]. In humans, low maternal folate status has also been associated with developmental delay and childhood behavioral difficulties such as hyperactivity and inattention [54,55], and also potentially in reducing the risk of autism-spectrum disorders [44,56] or in ameliorating the symptoms [57], hence continued supplementation throughout the entire gestational period may act as a preventative measure. Disruption in the conversion of homocysteine to methionine, via methionine synthase (MS) - a folate-dependent enzyme, has been shown to result in reduced D4 dopamine-stimulated phospholipid methylation required for neuronal synchronization and attention, which is often impaired in autism [58].

\section{Overview of brain development \& methylation changes}

Early development: 1st trimester \& neural tube closure

In humans, the development of the CNS commences with the formation of the neural plate post-gastrulation, around embryonic day 18 (e18), in a process known as neurulation (Figure 1A). The dorsal ectoderm thickens to form the neural plate, the edges of which elevate to form two neural folds with a depression in the middle - the neural groove (Figure 1B). When the extremities (each parallel fold) come into contact along the dorsal midline of the embryo, they fuse progressively to form the neural tube and separate from the adjacent ectoderm [19]. The open ends of the neural canal, or neuropores, are then sealed. This tubelike structure will develop into the brain and spinal cord, and becomes covered in the epidermal ectoderm. 
Closure of the neural tube, which is normally completed 28 days post-fertilization, is essential for brain development and correct skull formation. The neural tube does not close in a zipper-like fashion from one end to the other [59], but rather regionally (Figure 1B). Failure to close the last region in the sequence ( 5 in Figure 1B bottom) results in the most common NTD spina bifida, while failure to close the region corresponding to the mature cranium (region 2) will result in exposure of the neural tube to amniotic fluid and subsequent failure to develop, causing the more severe condition anencephaly. The role of folate and methylation of specific genes in these early events has been indicated above.

\section{Early-mid gestation: cell migration}

\section{\& differentiation}

Late in the fourth week of gestation, bursts of rapid cell division occur in zones along the neural tube causing bulging of the anterior end into three brain vesicles which demarcate the territories of the prosencephalon (forebrain), mesencephalon (midbrain) and the rhombencephalon (hindbrain). Subsequently, the prosencephalon vesicle divides once more to form the telencephalon and diencephalon (Figure 1C), while the rhombencephalon divides into the metencephalon and myelencephalon to give a total of five vesicles [60]. These are the progenitors of the major portions of the CNS within the skull - thus establishing the primary organization of the CNS. Of particular note for this review, the telencephalon will form the olfactory lobes, the primary region for processing scent almost immediately and later will form the hippocampus (memory storage) and cerebrum, while the diencephalon will form the retina and the hypothalamus (regulation of temperature, sleeping, breathing). Among the structures later formed by the metencephalon is the cerebellum, which coordinates muscular movement.

The neuroectodermal stem cells specified postgastrulation exist initially as NPCs. The NPC pool specified must undergo successive rounds of replication, from embryonic day e25-e42, prior to migration and differentiation into the billions of nonmitotic neurons which are produced by mid-gestation. Around e42, asymmetrical mitosis starts to occur, producing one NPC and one neuron per division. NPCs remain in the proliferative zone on the ventricular side of the neural tube, whereas neurons migrate outwards to form a marginal layer, with an intermediate zone between the two (Figure 1D). In the spine this basic three layer structure of ventricular (V), intermediate (I) and margin (M) is preserved and can be clearly distinguished in adult.

The cerebellum forms by a unique morphogenetic event (Figure 1E) during the first half of the second tri- mester, sprouting downward and involuting from an initial simple fold in the caudal hemisphere [19]. A layer of neuroblasts spread over the initial outer surface of the cerebellum so that in the maturing cerebellum a second proliferative layer, the external granular layer (EGL), distal to the ventricular zone is formed; from which mature nonmitotic neurons migrate inwards to form a marginal zone $(\mathrm{M})$. Beneath these are the Purkinje cells $(\mathrm{P})$, which form some of the largest and most highly branched of all neurons, with thousands of neurites per cell. Non-mitotic neurons migrating out from the ventricular zone, now called the ependymal layer (E) in the maturing tissue, form a second internal granular zone (IGL) (Figure 1E).

Maturation of the basic ventricular-intermediatemargin layers plays out differently during cortical development (Figure 1F). Here, neuroblasts migrate strictly outwards along glial cell processes toward the margin, with successive waves forming six distinct layers of in the cortical plate (CP) (Figure 1F), with the oldest neurons on the outside (layer 1) being those which migrated first, or had the earliest 'birthday' [61]. At the end of the third month, these cell migrations outwards from the ependymal layer to the surface or cortex of the brain, which are concentrated at the temporal (side) and frontal part of the brain, cause the surface to undergo more rapid expansion than the underlying layers, eventually leading to the formation of folds in the surface. The limbic lobe is the first part of the cortex to form, is associated with basic emotional responses and memory and is found deep in the middle part of the brain, behind where the stalk of the olfactory bulb attaches. The hippocampus forms as a projection into the telencephalon around 12-16 weeks and as it matures forms an important bridge for communication between the two hemispheres [19].

This process of histogenesis and cell migration will last well into the middle of gestation and is accompanied by dynamic changes in DNA methylation profile. As the neurons migrate outwards from the proliferative zone the levels of $5 \mathrm{hmC}$ increase greatly (Figure 2A). Hydroxymethylation first increases on enhancers associated with activation of neural genes, and is accompanied here by loss of 5-methylcystosine $(5 \mathrm{mC})$, suggesting that demethylation of tissue-specific enhancers is occurring [62]. Evidence for tissue-specific enhancers acting as pioneer sites for recruiting demethylation activity is supported by work from the Schübeler laboratory and others [63-65]. Consistent with this, the further products of demethylation such as 5-formylcytosine $(5 \mathrm{fC})$ and 5-carboxylcytosine $(5 \mathrm{caC})$ are also found at enhancers (Figure 2A) in differentiating neural cells [66]. Additionally, knockouts of TETI display a failure for NPC to develop into neurons in the hippocampus [67]. 
(A)

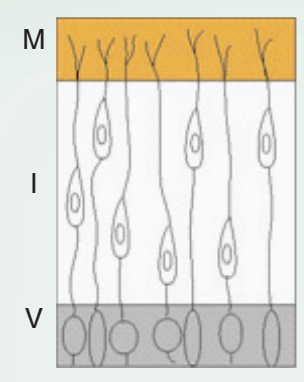

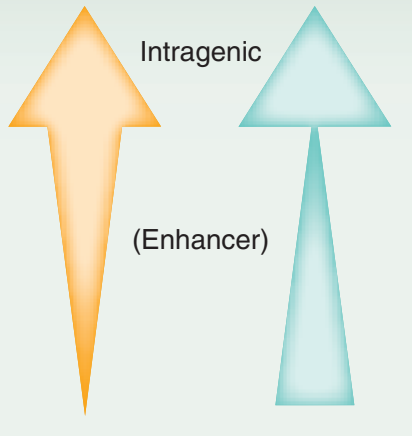

$5 \mathrm{hmC}$

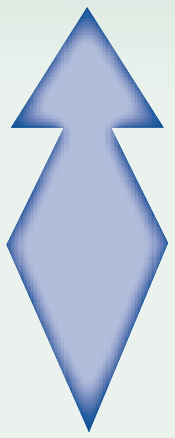

$5 f C, 5 \mathrm{caC}$
(Enhancer)

DNMT3A
(B)

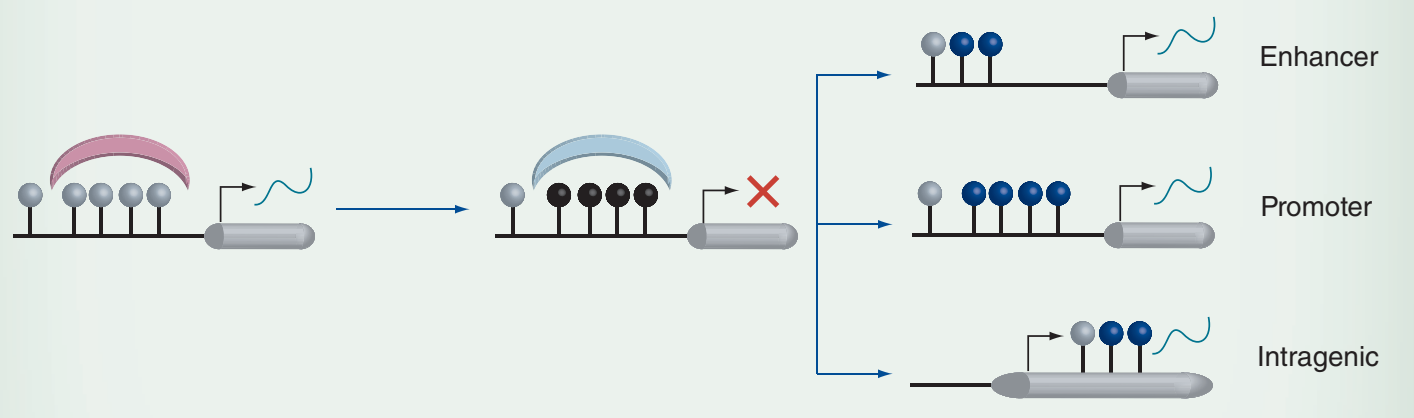

Figure 2. Alterations to methylation and hydroxymethylation during differentiation. (A) As neurons migrate from the $V$, levels of $5 \mathrm{hmC}$ generally increase. Additionally its localization changes, with enrichment at intragenic regions in the $\mathrm{M}$ but at enhancers in the I. DNMT3A expression (green arrow) also increases across the neural tube. Levels of $5 \mathrm{fC} / 5 \mathrm{caC}$ vary during migration, being more highly enriched in the enhancer regions particularly within the intermediate zone (blue arrow). (B) Methylation of naive DNA via DNMTs is often associated with transcriptional repression. This methylation can be reversed by TETs, which generate $5 \mathrm{hmC}$, usually associated with transcriptional activation. Hydroxymethylation at the enhancer and promoter appears to be more transient and likely reflects active demethylation in these regions, while intragenic $5 \mathrm{hmC}$ is more stable and may be continually required for optimal transcription rates.

5hmC: 5-hydroxymethylcytosine; DNMT: DNA methyltransferase; I: Intermediate zone; M: Marginal zone; TET: Ten eleven translocase; V: Ventricular zone.

After this initial wave, $5 \mathrm{hmC}$ levels decrease at enhancers and in the mature neurons (Figure $2 \mathrm{~B}$ ) and $5 \mathrm{hmC}$ is highest at intragenic sites instead $[66,68]$. In the mature neurons, increases in $5 \mathrm{hmC}$ are not accompanied by loss of $5 \mathrm{mC}$ or by increases in $5 \mathrm{fC}$ or $5 \mathrm{caC}$, suggesting that the $5 \mathrm{hmC}$ itself may act as a stable mark [69,70]. There is also recent evidence to show that $5 \mathrm{fC}$ may also be stable in the mature brain, with concentrations highest in neurons (rather than glial cells) in both cerebrum and cerebellum [66]. Supporting these results is the existence of a large group of proteins with high affinity for binding $5 \mathrm{hmC}[71,72]$. Ecker and colleagues also reported increases in $\mathrm{CpH}$ methylation ( $\mathrm{H}$ representing $\mathrm{A}, \mathrm{T}$ or $\mathrm{C}$ ) in maturing cells [73], which is known to be generated in large part by DNMT3A, and this de novo methyltransferase appears to play a particularly significant role in methylation in the brain [74,75]. The most prevalent methylated $\mathrm{CpH}$ dinucleotide is $\mathrm{CpA}$, which constitutes over $70 \%$ of non-CpG methylation in the frontal cortex.

Reader proteins, which can bind to these modified nucleotides and affect changes in transcription directly or indirectly, can be found at high levels in the mature brain, for example $\mathrm{MeCP} 2$, disruption of which leads 
to Rett syndrome, a neurological disorder with features of autism. MeCP2 can bind preferentially to $\mathrm{mCpH}$, specifically $\mathrm{mCpA}$ in adult mouse brain to repress expression of long genes which are associated with higher levels of mCA [76,77]. Furthermore, disruption of DNMT3A leads to transcriptional upregulation of long genes similar to the observed derepression of this subset of genes in MeCP2 disrupted models. The concurrent increase of $\mathrm{mCH}$ and $\mathrm{MeCP} 2$ from birth to adolescence suggests that $\mathrm{MeCP} 2$ binds $\mathrm{mCH}$ as neurons mature to regulate gene expression and suggests a mechanism for the delayed onset of MeCP2-related autism disorders.

\section{Mid-late gestation: neural arborization}

\& frontal cortex maturation

By the middle of the last trimester the cerebellum has formed and the six layers of the cortex can be distinguished (Figure 1F). The surface of the cerebral cortex, which is initially smooth, is forming the characteristic folds known as sulci and gyri, a process which will be completed prior to birth [19]. Many of the later histological events in human brain formation are still not fully characterized due to lack of accessibility. Myelination is known, however, to begin to occur, in waves, during this last trimester (Figure 1A, right) [78]. Arborization of the neural trees also occurs as the neurons mature. This leads to massive overproduction of synapses (synaptogenesis) such that the newborn has far more neural connections than adult [79]. Competition between synapses for those with the most efficient connections, and experiential inputs, lead to synaptic pruning and the mature neural structure [80]. Different areas of the brain undergo synaptic expansion and pruning at different times, with the bulk of this occurring in the first few years of life, but the process has already begun for the auditory and visual cortices prior to birth. During the last trimester the cortex as a whole matures, and while key functions of the brain are dependent on a distributed network of neurons in multiple areas, mapping in adult beginning with the seminal work of Penfield and Rasmussen [81] and, more recently using techniques such as magnetoencephalography (MEG) (Box 1 \& Figure 3), has nevertheless identified some well-defined areas which are particularly important for many key functions (Figure 1G). Examples include regions such as the somatosensory area involved in feedback control of muscles, the occipital region involved in visual processing, as well as areas crucial for language, such as Broca's and Wernicke's areas (Figure 1G), the foundations for which are laid in this late period of prenatal growth. One of the latest to mature, the preoptic area (POA) is of particular interest and shows sex-specific differences in mammals: it matures perinatally in rodents and, it is thought, in humans. The sexual dimorphism in the POA established in this period governs the pituitary release of gonadotropins later in life and copulatory behavior [82]

\section{Neuronal targets associated with methylation changes}

\section{Early gestation}

Early specification of the regions of the brain is dependent on key signaling molecules such as Noggin, Chordin and Follistatin for the rostral area, while the caudal or hindbrain region is initially specified by retinoic acid, WNT and FGF. The Homeobox genes, which are highly conserved through evolution, are key specifiers of hindbrain development acting downstream from the initial morphogenetic signals. Genes in the proximal or $5^{\prime}$ ends of each of the four HOX clusters in human are involved in specification of rhombomeres (Figure 1A) in the hindbrain [86]. Methylation at the HOXA cluster has recently been shown to play a key role in regulating the transcriptional activation of these genes [87]. The cluster is initially methylated in the early postimplantation wave of methylation in the embryo, and demethylation of the genes is associated with increased $5 \mathrm{hmC}$ levels.

$B D N F$ is critically important for neurogenesis and survival of nerve cells from early in development onward, and misregulation of the gene has been implicated in a number of neurological disorders [88]. Increased methylation at the promoter region for example is associated with transcriptional repression [89]. This repression is associated with chromatin remodeling via methyl-CpG-binding proteins such as MeCP2. Martinowich et al. and Chen et al. showed that a decrease in $B D N F$ methylation in the promoter region mediates sustained elevation of $B D N F$ transcription in long-term culture of cortical neurons [90,91].

The $P C D H$ genes likewise appear to play an important neuroprotective role in early brain development. The C-class protocadherins in particular are vital for neuronal survival at this early stage and deletion of these genes results in increased apoptosis in the brain, a smaller overall brain volume and perinatal death [92]. Methylation is important for controlling transcription of some protocadherins [93] though a role in regulating the C-class has not been firmly established.

\section{Mid gestation}

A large number of genes require epigenetic modifications for regulating their expression, but no gene class discovered are more critically dependent upon DNA methylation than the imprinted genes [94]. Contrary to the majority of autosomal genes, imprinted genes are expressed monoallelically, where the repressed allele is 


\section{Box 1. Brain imaging and magnetoencephalography.}

- Longitudinal studies of human brain function require an inexpensive, noninvasive and relatively subject-friendly form of brain imaging. It has been recommended by the International Life Sciences Institute that nutritional intervention studies involving cognitive function should include monitoring of brain imaging biomarkers [83]. A number of options are available [84], including MRI, near InfraRed spectroscopy (nearlR) and magnetoencephalography. MRI has a long track record of use and can determine both structural and functional characteristics, the latter through techniques such as measuring blood flow to active neurons: however, longer acquisition times are required than some other techniques and for young subjects, lying still in a confined space can be daunting. While nearlR is comparatively cheap, simple to use and analyze, it cannot provide information on anything but the upper layers of the cortex. Magnetoencephalography is an attractive approach in terms of being low-cost but with good temporal and spatial resolution. For studies involving children it is particularly appealing due to the non-invasive nature of the scanner, which allows the subject to be scanned while seated and can be done in multiple short runs of 3-5 min (Figure 3). It can monitor various functional regions including sensory, motor, language and memory regions and can observe deeper neural sources as well, though accuracy decreases with depth [85].

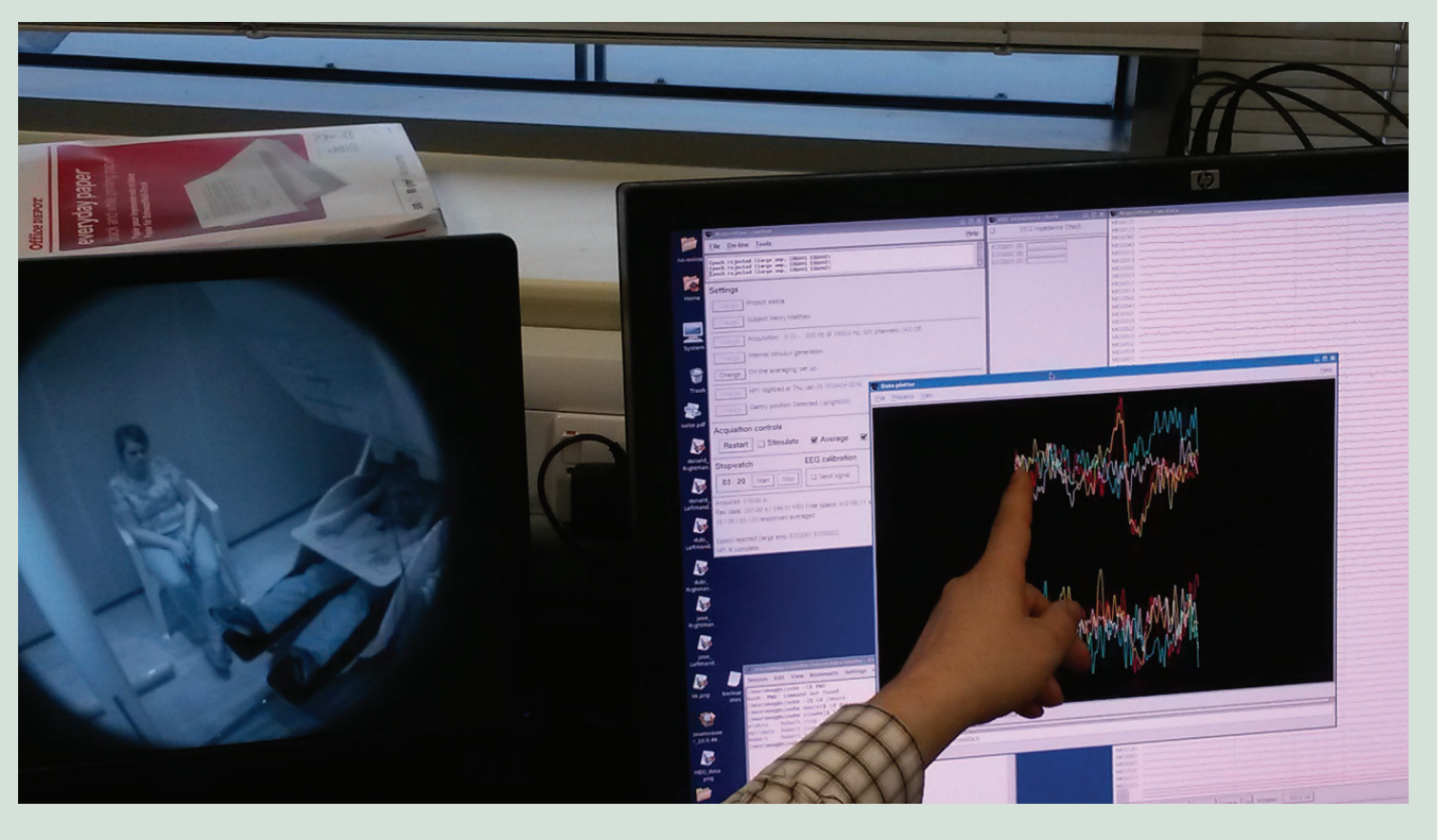

Figure 3. Magnetoencephalography scanning of child aged 8 years and corresponding signal output. Magnetoencephalography scanning of boy aged 8 years shows user-friendly, non-invasive system with corresponding brain activity measurement on screen.

marked by parent-specific methylation [95]. Imprinted genes play several important roles throughout life, including embryonic growth control, X-chromosome inactivation and placental development. This particular gene class has been highlighted as key modulators of developmental plasticity, due to their known requirement in early-mid gestation.

Imprinted genes are regulated by cis-acting elements known as differentially methylated regions (DMRs). The majority of imprint marks are established as DMRs in the female germline by DNMT3A and its noncatalytic cofactor DNMT3L via de novo methylation [96,97], and this allele-specific methylation is retained throughout the epigenetic reprogramming of early development to maintain monoallelic expression in the somatic tissues of the conceptus [98]. Imprinted genes have a tendency to exist in clusters, sharing a single DMR [99]. Once perturbed, no mechanism has been identified to restore normal methylation levels [100]. Thus changes in DMR methylation could potentially alter the expression of multiple imprinted genes [94].

It has been suggested that these genes are more susceptible to dosage perturbation due to early life environmental challenges $[5,101,102]$. Ferguson-Smith and Bartolomei suggest the opposite is true and that in fact imprinted genes may have some innate protection against environmental exposures, which some recent studies support $[30,94]$. 
Interestingly, the majority of known imprinted genes are highly expressed in neural tissue, and many are solely expressed here [103]. Perturbation in imprinted gene methylation gives rise to serious human imprinting disorders, such as Prader-Willi syndrome (PWS) and Angelman syndrome (AS) [86,104]. These imprinting disorders are characterized by behavioral, cognitive and other neurological impairments, indicating the importance of imprinting in brain development and function $[105,106]$. Dependency upon DNA methylation for establishment and regulation highlights imprinted genes as potentially vulnerable targets of developmental programming which could be mediated by suboptimal nutritional status in utero [18].

The brain is postulated to be the most plastic of all mammalian tissues, responsible for behavior, learning, memory and cognition. DNA methyltransferase enzymes exist at concentrated levels within neural tissue $[107,108]$ thus one may hypothesise that perturbation in global folic acid status in an area deemed high in imprinted gene expression also may have considerable effect on the neurological function of the offspring. Several animal studies have highlighted that maternal nutrition may influence the cognitive health of the offspring [109-111] yet few have characterized folic acid status in relation to cognitive development [112]. With the known importance of folate in normal brain development, and the fact that a large proportion of genes expressed in the brain display a degree of imprinted expression, it is important to pursue potential environmental factors which may alter proper establishment of methylation marks. However, Kelsey notes that many newly identified loci are more 'weakly' imprinted, and perhaps therefore have a greater innate plasticity in response to environmental cues [113]. This view is supported by Meaney and Ferguson who suggest the mammalian brain to have evolved 'highly sensitive' integrated epigenetic mechanisms which allow cellular memory of neural experience but also innate plasticity to environmental cues [114].

Both $B D N F$ and the protocadherins play roles at this later stage of brain development as well as earlier. Dynamic changes in DNA methylation within the promoter region of $B D N F$ were shown for example to influence neural plasticity via the regulation of activity-dependent neuronal genes [115]. The variable class protocadherins such as the $\mathrm{A}$ - and $\mathrm{B}$-class genes at the gamma cluster, appear to play crucial roles in neuron architecture. Cells such as Purkinje neurons which have thousands of neurites require a system to distinguish their own neurites from those of others. The protocadherins appear to be the key molecules allowing cells to distinguish self from non-self, and their loss leads to a collapse of normal Purkinje cellular architec- ture together with multiple self-interactions among an individual cells neurites [116]. Methylation at the promoters of the variable class genes has been shown in mice to play an important role in their suppression [93]. Interestingly, the variable class genes are expressed from just one of the two parental alleles (i.e. are monoallelic) [117]. However, unlike imprinted genes this does not depend on the parent-of-origin of the allele.

In the olfactory epithelium, maturation of the sensory cells is accompanied by selection of a single olfactory receptor (OR) for expression. The OR gene family is possibly the largest of all human gene families, comprising over 600 active members and many pseudogenes [118]. The mechanism for specifying which OR to express in a given cell is so efficient that it not only selects one gene from this array but even one allele, resulting in monoallelic expression for this brain gene class as well. As for imprinted genes and the protocadherins, inactive promoters are associated with high levels of DNA methylation, as well as other marks of inactive chromatin and a role for DNMT3A in regulating these genes has recently been established [119].

\section{Late gestation}

Many of the genes mentioned above for mid-gestation also have roles in the late brain, including $B D N F$, the imprinted genes and protocadherins. With respect to structures which arise late in gestation, the POA is of particular interest, as recent work has shown that males have lower DNMT activity in this region. The injection of small-molecule methyltransferase inhibitors into the lateral ventricle of the cerebrum, or tissue-specific KO of the DNMT3A gene, gave partial masculinization of female mice both neurohistologically and in terms of gene expression, highlighting an important role for methylation via this enzyme in suppression of the male transcriptome and in longterm maintenance of the female sexual neurocognitive program [120]. DNMT3A also plays an important part in in $\mathrm{CpH}$ methylation as mentioned previously, and levels of this modification also begin to rise in the period immediately postnatal in mouse brain, and the targets of $\mathrm{CpH}$ methylation such as OPCML, SOX6 and FXD3 are conserved to some degree between mouse and human $[73,121]$.

Recent work has identified key genes involved in language acquisition in humans, a number of which are found on Chr.7 between 7q31 and 7q35 and which are co-ordinately regulated by the transcription factor FOXP2. One such target is CNTNAP2 a member of the neurexin family, expressed at high levels in the developing human cortex and which appears to show differential methylation between humans and our closest relative the chimp [122]. Both FOXP2 and CNTNAP2 are 
implicated in syndromes involving language impairment, including Tourette's, autism spectrum disorders (ASDs) and attention-deficit disorder.

Methylation differences have also been found at a number of other important neurodevelopmental genes with links to human behavioral and neurocognitive disabilities, a partial list of which is given in Table 1.

\section{Conclusion \& future perspective}

The field of human neuroepigenetics remains in its infancy, and the emerging picture of how the newborn neuro-epigenome is shaped remains complex [136]. Future in-depth interrogations of multiple human tissue epigenomes and compilation of clinical outcomes are warranted; this is especially pertinent when considering the effects of folate status specifically on the brain. In the future we are likely to see increasing application of epigenome-wide association studies to large preexisting cohorts collected either as part of genome sequencing initiatives such as the $100 \mathrm{~K}$ genomes project [137] or as longitudinal social surveys, where there exists extensive phenotypic data, such as the Avon longitudinal study of parents and children [138]. The power of these approaches will lie in the large numbers involved, and the added value of parallel analyses of multiple features of the cohort, such as social, behavioral, health and cognitive data on the subjects. We foresee increasing interdisciplinary collaboration between diverse subjects such as psychology, nutrition, epidemiology, brain imaging and molecular biology and the building of multidisciplinary teams to collect, analyze, cross-correlate and interpret the high-dimensional data obtained. The use of sophisticated techniques such as Mendelian randomization [10] will help to control for confounders in these datasets. Microarray-based methylation analyses such as the EPIC and $450 \mathrm{~K}$ arrays [139] are likely to still play an important role given their affordability, accuracy and high reproducibility while algorithms based on the DNA methylation data can extract novel, informative features of the sample set such as methylation age [140] and control for unequal cell type profiles among subjects [141]. The development of techniques to assay $5 \mathrm{mC}$ and other modifications on these arrays will allow a more complete methylation profile to be built [142]. In addition to the large retrospective studies it will be important to utilize randomized controlled trials (such as the FASSTT study [143]), while these are likely to be much smaller in size, they remain the gold standard in clinical and social sciences.

\begin{tabular}{|c|c|c|c|c|}
\hline Brain disorder & $\begin{array}{l}\text { Role for } \\
\text { folate? }\end{array}$ & $\begin{array}{l}\text { Gene(s) } \\
\text { implicated }\end{array}$ & Description/methylation status & Ref. \\
\hline $\begin{array}{l}\text { NTD: } \\
\text { - Anencephaly } \\
\text { - Spina bifida }\end{array}$ & Yes & MTHFR & Decreased methylation $(-0.33 \%)$ in NTD cases & {$[124$} \\
\hline $\begin{array}{l}\text { Imprint disorders: } \\
\text { - Prader-Willi syndrome } \\
\text { - Angelman syndrome }\end{array}$ & No & $\begin{array}{l}\text { SNURFISNRPN } \\
\text { (snORNAs) }\end{array}$ & $\begin{array}{l}\text { Deficiency of paternally-expressed imprinted transcripts } \\
\text { (SNURF-SNRPN and HBII-85 snoRNAs) }\end{array}$ & [126] \\
\hline Rett syndrome & No & $\mathrm{MeCP} 2$ & Mutations in MeCP2 leading to epigenetic dysregulation & [127] \\
\hline \multirow[t]{4}{*}{$\begin{array}{l}\text { Autism spectrum } \\
\text { disorders }\end{array}$} & \multirow[t]{4}{*}{ No } & $B C L 2, R O R A$ & $\begin{array}{l}\text { Hypermethylation of } 5^{\prime} \mathrm{CGI} \text {, downregulation and decreased } \\
\text { protein levels in postmortem autism spectrum disorder brain }\end{array}$ & [128] \\
\hline & & MECP2 & $\begin{array}{l}\text { Decreased } M E C P 2 \text { expression with increased promoter } \\
\text { methylation in ASD frontal cortex }\end{array}$ & [131] \\
\hline & & EN2 & $\begin{array}{l}\text { Hypermethylation, overexpression, increased protein levels } \\
\text { with H3K } 27 \text { me3 loss/H3K4me3 gain in ASD cerebellum }\end{array}$ & [132] \\
\hline & & OXTR & $\begin{array}{l}\text { Hypermethylation in ASD temporal cortex with decreased } \\
\text { expression }\end{array}$ & [133] \\
\hline \multirow[t]{2}{*}{ Fragile-X syndrome } & \multirow[t]{2}{*}{ Yes } & FMR-1 & Hypermethylation/reduced expression & [134] \\
\hline & & $A F F 2(F M R-2)$ & Hypermethylation/reduced expression in brain & [135] \\
\hline
\end{tabular}


Acknowledgements

The authors are grateful to A Caffrey and L-A Henry for valuable discussions.

Financial \& competing interests disclosure

Work in the authors' laboratories is supported by an Enabling Research Award STL/5043/14) from the HSC Research and Development Division of the Public Health Agency, Northern Ireland (to K Pentieva, CP Walsh and H McNulty), an MRC project grant (MR/J007773/1 to CP Walsh) and an Epigenetics Initiative grant from the ESRC/BBSRC (the EpiFASSTT study ES/N000323/1 to CP Walsh, K Pentieva, T Cassidy, H McNulty,
DL Lees-Murdock, M McLaughlin and G Prasad). The authors have no other relevant affiliations or financial involvement with any organization or entity with a financial interest in or financial conflict with the subject matter or materials discussed in the manuscript apart from those disclosed.

No writing assistance was utilized in the production of this manuscript.

\section{Open access}

This work is licensed under the Attribution-NonCommercialNoDerivatives 4.0 Unported License. To view a copy of this license, visit http://creativecommons.org/licenses/by-nc-nd/4.0/

Executive summary

- Recent work in molecular biology has shown that DNA methylation in the brain is more dynamic than previously thought.

- Simultaneously, epigenome-wide analyses of large cohorts collected as part of social or health science epidemiological work has shown association between DNA methylation changes and particular sociocognitive outcomes.

- A key nutrient required for DNA methylation during development is folate, which provides the universal methyl donor S-adenosylmethionine.

- Folate insufficiency of the pregnant mother in the first trimester provides a clear example where environmental input in the mother alters neurocognitive outcomes in the offspring.

- Folate or other environmental variables may affect methylation patterns throughout development but this remains to be explored.

- We highlight in this review points key stages during fetal brain development where dynamic methylation changes occur and may potentially be perturbed.

- Neural tube closure early in the first trimester is sensitive to folate insufficiency, which can result in neural tube defects and this effect can be mimicked by DNA methyltransferase inhibitors.

- During early-to-mid gestation waves of differentiating neurons move radially outwards in the neural tube from the stem cell layer on the interior, vesicular side.

- During the second trimester the cerebellum forms and there is histological maturation of the cortex and cerebellum as migration ceases.

- In the third trimester myelination and the initiation of synaptogenesis occur, as well as the maturation of the cerebral cortex and emergence of regions specialised to execute higher cognitive abilities.

- Migration of cells outward in the neural tube is accompanied by dynamic changes in methylation, with an increase in $5 \mathrm{hmC}$ and $\mathrm{CpH}$ methylation in the maturing neurons as transcriptional programs are established.

- As well as likely being important for specific genes such as BDNF and CNTNAP2 methylation has an established role in controlling the $H O X, O R$ and $P C D H$ gene families involved in neural development.

- DNA methylation changes have been implicated in a number of neurocognitive disorders in addition to neural tube defects, including Angelman syndrome, autism spectrum disorders and Rett syndrome.

\section{References}

Papers of special note have been highlighted as:

- of interest; $\bullet \bullet$ of considerable interest

1 Kriaucionis S, Heintz N. The nuclear DNA base 5-hydroxymethylcytosine is present in Purkinje neurons and the brain. Science 324(5929), 929-930 (2009).

2 Tahiliani M, Koh KP, Shen Y et al. Conversion of 5-methylcytosine to 5-hydroxymethylcytosine in mammalian DNA by MLL partner TET1. Science 324(5929), 930-935 (2009).

3 Lister R, Mukamel E, Nery JR et al. Global epigenomic reconfiguration during mammalian brain development. Science 341(6146), 1237905 (2013).
-. This insightful study involved single-base resolution of DNA methylation and hydroxymethylation ontogeny in human and mouse brain.

4 Barker DJP. The developmental origins of chronic adult disease. Acta Paediatr. Suppl. 93(446), 26-33 (2004).

- An influential review on developmental plasticity in response to environmental cues and related adulthood disease.

5 Heijmans BT, Tobi EW, Stein AD et al. Persistent epigenetic differences associated with prenatal exposure to famine in humans. Proc. Natl Acad. Sci. USA 105(44), 17046-17049 (2008).

- A well-known example in human of how prenatal exposure to famine in utero led to changes in DNA 
methylation which persisted up to six decades later in the individual.

6 Barker D. Infant mortality, childhood nutrition, and ischaemic heart disease in England and Wales. Lancet 327(8489), 1077-1081 (1986).

7 Tobi EW, Goeman JJ, Monajemi R et al. DNA methylation signatures link prenatal famine exposure to growth and metabolism. Nat. Commun. 5, 5592 (2014).

8 McNulty B, Pentieva K, Marshall B et al. Womens compliance with current folic acid recommendations and achievement of optimal vitamin status for preventing neural tube defects. Hum. Reprod. 26(6), 1530-1536 (2011).

9 Yiu TT, Li W. Pediatric cancer epigenome and the influence of folate. Epigenomics 7(6), 961-973 (2015).

10 Kirkbride JB, Susser E, Kundakovic M et al. Prenatal nutrition, epigenetics and schizophrenia risk: can we test causal effects? Epigenomics 4(3), 303-315 (2012).

11 Copp AJ, Greene NDE. Neural tube defects-disorders of neurulation and related embryonic processes. Wiley Interdiscip. Rev. Dev. Biol. 2(2), 213-227 (2013).

12 Eskes TK. Open or closed? A world of difference: a history of homocysteine research. Nutr. Rev. 56(8), 236-244 (1998).

13 Czeizel AE, Dudás I. Prevention of the first occurrence of neural-tube defects by periconceptional vitamin supplementation. N. Engl. J. Med. 327(26), 1832-1835 (1992).

14 Smithells RW, Sheppard S, Schorah CJ. Vitamin deficiencies and neural tube defects. Arch. Dis. Child. 51(12), 944-950 (1976).

15 MRC Vitamin Study Research Group. Prevention of neural tube defects: results of the Medical Research Council Vitamin Study. Lancet 338(8760), 131-137 (1991).

16 Talaulikar VS, Arulkumaran S. Folic acid in obstetric practice: a review. Obstet. Gynecol. Surv. 66(4), 240-247 (2011).

17 Cheschier N, ACOG Committee on Practice BulletinsObstetrics. American College of Obstetricians and Gynecologists. Neural tube defects. Int. J. Gynaecol. Obstet. 83(1), 123-133 (2003).

18 Crider KS, Bailey LB, Berry RJ. Folic acid food fortificationits history, effect, concerns, and future directions. Nutrients 3(3), 370-384 (2011).

19 Collins P. Development of the nervous system. In: Gray's Anatomy. Standing S (Ed.). Elsevier, Edinburgh, Scotland, 241-274 (2005).

20 Gilbert SF. Developmental Biology (6th Edition). Sinauer Associates, MA, USA, 271 (2000).

21 Botto LD, Yang Q. 5,10-Methylenetetrahydrofolate reductase gene variants and congenital anomalies: a HuGE review. Am. J. Epidemiol. 151(9), 862-877 (2000).

22 Piedrahita JA, Oetama B, Bennett GD et al. Mice lacking the folic acid-binding protein Folbp1 are defective in early embryonic development. Nat. Genet. 23(2), 228-232 (1999).

23 Spiegelstein O, Mitchell LE, Merriweather MY et al. Embryonic development of folate binding protein-1 (Folbp1) knockout mice: Effects of the chemical form, dose and timing of maternal folate supplementation. Dev. Dyn. 231(1), 221-231 (2004).

24 Barber RC, Lammer EJ, Shaw GM et al. The role of folate transport and metabolism in neural tube defect risk. Mol. Genet. Metab. 66(1), 1-9 (1999).

25 Fleming A, Copp AJ. Embryonic folate metabolism and mouse neural tube defects. Science 280 (5372), 2107-2109 (1998).

26 Beaudin AE, Abarinov EV, Noden DM et al. Shmt1 and de novo thymidylate biosynthesis underlie folate-responsive neural tube defects in mice. Am. J. Clin. Nutr. 93(4), 789-798 (2011).

27 Beaudin AE, Abarinov EV, Malysheva O et al. Dietary folate, but not choline, modifies neural tube defect risk in Shmt1 knockout mice. Am. J. Clin. Nutr. 95(1), 109-114 (2012).

28 Christensen KE, Deng L, Leung KY. A novel mouse model for genetic variation in 10-formyltetrahydrofolate synthetase exhibits disturbed purine synthesis with impacts on pregnancy and embryonic development. Hum. Mol. Genet. 22(8), 3705-3719 (2013).

29 Carroll N, Pangilinan F, Molloy AM et al. Analysis of the MTHFD1 promoter and risk of neural tube defects. Hum. Genet. 125(3), 247-256 (2009).

30 Ivanova E, Chen JH, Segonds-Pichon A et al. DNA methylation at differentially methylated regions of imprinted genes is resistant to developmental programming by maternal nutrition. Epigenetics 7(10), 1200-1210 (2012).

31 Dunlevy LPE, Burren KA, Mills K et al. Integrity of the methylation cycle is essential for mammalian neural tube closure. Birth Defects Res. Part A Clin. Mol. Teratol. 76(7), 544-552 (2006).

- Adequate functioning of the DNA methylation cycle is essential for cranial neural tube closure.

32 Moephuli SR, Klein NW, Baldwin MT et al. Effects of methionine on the cytoplasmic distribution of actin and tubulin during neural tube closure in rat embryos. Proc. Natl Acad. Sci. USA 94(2), 543-548 (1997).

33 Afman LA, Blom HJ, Drittij MJ et al. Inhibition of transmethylation disturbs neurulation in chick embryos. Dev. Brain Res. 158(1-2), 59-65 (2005).

34 Okano M, Bell DW, Haber DA et al. DNA methyltransferases Dnmt3a and Dnmt3b are essential for de novo methylation and mammalian development. Cell 99(3), 247-257 (1999).

35 Wang L, Wang F, Guan J et al. Relation between hypomethylation of long interspersed nucleotide elements and risk of neural tube defects. Am. J. Clin. Nutr. 91(5), 1359-1367 (2010).

36 Chang $\mathrm{H}$, Zhang $\mathrm{T}$, Zhang $\mathrm{Z}$ et al. Tissue-specific distribution of aberrant DNA methylation associated with maternal low-folate status in human neural tube defects. J. Nutr. Biochem. 22(12), 1172-1177 (2011).

37 Reynolds E. Vitamin B12, folic acid, and the nervous system. Lancet Neurol. 5(11), 949-960 (2006).

38 Georgieff MK. Nutrition and the developing brain: nutrient priorities and measurement. Am. J. Clin. Nutr. 85(2), S614-S620 (2007). 
39 Anjos T, Altmäe S, Emmett P et al. Nutrition and neurodevelopment in children: focus on NUTRIMENTHE project. Eur. J. Nutr. 52(8), 1825-1842 (2013).

40 Akchiche N, Bossenmeyer-Pourié C, Kerek R et al. Homocysteinylation of neuronal proteins contributes to folate deficiency-associated alterations of differentiation, vesicular transport, and plasticity in hippocampal neuronal cells. FASEB J. 26(10), 3980-3992 (2012).

41 Kruman II, Mouton PR, Emokpae R et al. Folate deficiency inhibits proliferation of adult hippocampal progenitors. Neuroreport 16(10), 1055-1059 (2005).

42 Blaise SA, Nédélec E, Schroeder $\mathrm{H}$ et al. Gestational vitamin B deficiency leads to homocysteine-associated brain apoptosis and alters neurobehavioral development in rats. Am. J. Pathol. 170 (2), 667-679 (2007).

43 Craciunescu CN, Brown EC, Mar M-H et al. Folic acid deficiency during late gestation decreases progenitor cell proliferation and increases apoptosis in fetal mouse brain. J. Nutr. 134(1), 162-166 (2004).

44 Barua S, Kuizon S, Chadman KK et al. Single-base resolution of mouse offspring brain methylome reveals epigenome modifications caused by gestational folic acid. Epigenetics Chromatin. 7(1), 3 (2014).

-. Folic acid-mediated changes in neural DNA methylation augmented by maternal diet at a single-base resolution and corresponding changes in gene expression.

45 Julvez J, Fortuny J, Mendez M et al. Maternal use of folic acid supplements during pregnancy and four-year-old neurodevelopment in a population-based birth cohort. Paediatr. Perinat. Epidemiol. 23(3), 199-206 (2009).

46 Phase III, Krishnaveni GV, Srinivasan K et al. Higher maternal plasma folate but not vitamin B-12 concentrations during pregnancy are associated with better cognitive function scores in 9-to-10 year-old children in South India. J. Nutr. 140(5), 1014-1022 (2010).

- Elegant study of how maternal intake of folic acid is associated with higher cognition in children exposed during pregnancy.

47 Chatzi L, Papadopoulou E, Koutra K et al. Effect of high doses of folic acid supplementation in early pregnancy on child neurodevelopment at 18 months of age: the mother-child cohort "Rhea" study in Crete, Greece. Public Health Nutr. 15(09), 1728-1736 (2012).

48 Roth C, Magnus P, Schjølberg S et al. Folic acid supplements in pregnancy and severe language delay in children. Obstet. Gynecol. Surv. 67(2), 79-80 (2012).

49 Villamor E, Rifas-Shiman SL, Gillman MW et al. Maternal intake of methyl-donor nutrients and child cognition at 3 years of age. Paediatr. Perinat. Epidemiol. 26(4), 328-335 (2012).

50 De Graaf-Peters VB, Hadders-Algra M. Ontogeny of the human central nervous system: what is happening when? Early Hum. Dev. 82(4), 257-266 (2006).

51 Gross RL, Newberne PM, Reid JVO. Adverse effects on infant development associated with maternal folic acid deficiency. Nutr. Rep. Int. 10(5), 241-248 (1974).
52 Pentieva K, McGarel C, McNulty B et al. Effect of folic acid supplementation during pregnancy on growth and cognitive development of the offspring: a pilot follow-up investigation of children of FASSTT study participants. Proc. Nutr. Soc. doi:10.1017/S0029665112001966 (2012) (Epub ahead of print).

53 Del Río Garcia C, Torres-Sánchez L, Chen J et al. Maternal MTHFR $677 \mathrm{C}>\mathrm{T}$ genotype and dietary intake of folate and vitamin B (12): their impact on child neurodevelopment. Nutr. Neurosci. 12(1), 13-20 (2009).

54 Roza SJ, van Batenburg-Eddes T, Steegers EAP et al. Maternal folic acid supplement use in early pregnancy and child behavioural problems: The Generation R Study. Br. J. Nutr. 103(3), 445-452 (2010).

55 Steenweg-de Graaff J, Roza SJ, Steegers EA et al. Maternal folate status in early pregnancy and child emotional and behavioral problems: the Generation R Study. Am. J. Clin. Nutr. 95(6), 1413-1421 (2012).

56 Surén P, Roth C, Bresnahan M et al. Association between maternal use of folic acid supplements and risk of autism spectrum disorders in children. JAMA 309(6), 570-577 (2013).

57 Gillberg C, Ohlson VA, Wahlström J, Steffenburg S, Blix K. Monozygotic female twins with autism and the fragile-X syndrome (AFRAX). J. Child Psychol. Psychiatry 29(4), 447-451 (1988).

58 Deth R, Muratore C, Benzecry J et al. How environmental and genetic factors combine to cause autism: a redox/ methylation hypothesis. Neurotoxicology 29(1), 190-201 (2008).

59 Van Allen MI, Kalousek DK, Chernoff GF et al. Evidence for multi-site closure of the neural tube in humans. $\mathrm{Am}$. J. Med. Genet. 47, 723-743 (1993).

60 Moore KL, Persaud TVN. Before We Are Born: Essentials of Embryology and Birth Defects. Elsevier, Philidelphia, USA (2012).

61 Rakic P. Neurons in rhesus monkey visual cortex: systematic relation between time of origin and eventual disposition. Science 183(4123), 425-427 (1974).

62 Wen L, Li XX, Yan L et al. Whole-genome analysis of 5-hydroxymethylcytosine and 5-methylcytosine at base resolution in the human brain. Genome Biol. 15(3), R49 (2014).

63 Smale ST. Pioneer factors in embryonic stem cells and differentiation. Curr. Opin. Genet. Dev. 20(5), 519-526 (2010).

64 Feldmann A, Ivanek R, Murr R et al. Transcription factor occupancy can mediate active turnover of DNA methylation at regulatory regions. PLoS Genet. 9(12), e1003994 (2013).

65 Zaret KS, Carroll JS. Pioneer transcription factors: establishing competence for gene expression. Genes Dev. 25(21), 2227-2241 (2011).

66 Wheldon LM, Abakir A, Ferjentsik Z et al. Transient accumulation of 5-carboxylcytosine indicates involvement of active demethylation in lineage specification of neural stem cells. Cell Rep. 7(5), 1353-1361 (2014). 
RR, Cui QY, Murai K et al. Tet1 regulates adult hippocampal neurogenesis and cognition. Cell Stem Cell. 13(2), 237-245 (2013).

68 Jin SG, Wu X, Li AX et al. Genomic mapping of 5-hydroxymethylcytosine in the human brain. Nucleic Acids Res. 39(12), 5015-5024 (2011).

69 Hahn MA, Qiu R, Wu X et al. Dynamics of 5-hydroxymethylcytosine and chromatin marks in mammalian neurogenesis. Cell Rep. 3(2), 291-300 (2013).

70 Hahn MA, Szabo PE, Pfeifer GP et al. 5-Hydroxymethylcytosine: a stable or transient DNA modification? Genomics 10(5), 314-323 (2014).

71 Iurlaro M, Ficz G, Oxley D et al. A screen for hydroxymethylcytosine and formylcytosine binding proteins suggests functions in transcription and chromatin regulation. Genome Biol. 14(10), R119 (2013).

72 Spruijt CG, Gnerlich F, Smits AH et al. Dynamic readers for 5-(hydroxy) methylcytosine and its oxidized derivatives. Cell 152(5), 1146-1159 (2013).

73 Lister R, Mukamel EA, Nery JR et al. Global epigenomic reconfiguration during mammalian brain development. Science 341(6146), 1237905 (2013).

74 Feng J, Zhou Y, Campbell SL et al. Dnmt1 and Dnmt3a maintain DNA methylation and regulate synaptic function in adult forebrain neurons. Nat. Neurosci. 13(4), 423-430 (2010).

75 LaPlant Q, Vialou V, Covington HE et al. Dnmt3a regulates emotional behavior and spine plasticity in the nucleus accumbens. Nat. Neurosci. 13(9), 1137-1143 (2010).

76 Chen L, Chen K, Lavery LA et al. MeCP2 binds to nonCG methylated DNA as neurons mature, influencing transcription and the timing of onset for Rett syndrome. Proc. Natl Acad. Sci. USA 112(17), 201505909 (2015).

77 Gabel HW, Kinde B, Stroud H et al. Disruption of DNA-methylation-dependent long gene repression in Rett syndrome. Nature 522(7554), 89-93 (2015).

78 Thompson R, Nelson C. Developmental science and the media: early brain development. Am. Psychol. 56(1), 5-15 (2001).

79 Peter RH. Synaptic density in human frontal cortexdevelopmental changes and effects of aging. Brain Res. 163(2), 195-205 (1979).

80 Kandel ER, Jessell TM, Sanes JR. Sensory experience and the fine-tuning of synaptic connections. In: Principles of Neural Science. Kandel ER, Schwartz JH, Jessell TM (Eds). McGraw-Hill, New York, USA, 1115-1130 (2000).

81 Penfield W, Rasmussen T. The cerebral cortex of man. A clinical study of localization of function. Acad. Med. 25, 375 (1950).

82 Morris JA, Jordan CL, Breedlove SM. Sexual differentiation of the vertebrate nervous system. Nat. Neurosci. 7(10), 1034-1039 (2004).

83 De Jager CA, Dye L, De Bruin E et al. Cognitive function: criteria for validation and selection of cognitive tests for investigating the effects of foods and nutrients. Nutr. Rev. 72(3), 162-179 (2014).
84 Sizonenko SV, Babiloni C, de Bruin EA et al. Brain imaging and human nutrition: which measures to use in intervention studies? Br. J. Nutr. 110(Suppl.), S1-S30 (2013).

85 Stufflebeam SM, Rosen BR. Mapping cognitive function. Neuroimaging Clin. N. Am. 17(4), 469-484, vii-ix (2007).

86 Wilkinson DG, Bhatt S, Cook M et al. Segmental expression of Hox-2 homoeobox-containing genes in the developing mouse hindbrain. Nature 341(6241), 405-409 (1989).

87 Bocker MT, Tuorto F, Raddatz G et al. Hydroxylation of 5-methylcytosine by TET2 maintains the active state of the mammalian HOXA cluster. Nat. Commun. 3, 818 (2012).

88 Karpova NN. Role of $B D N F$ epigenetics in activitydependent neuronal plasticity. Neuropharmacology 76(Pt C), 709-718 (2014).

89 Suzuki MM, Bird A. DNA methylation landscapes: provocative insights from epigenomics. Nat. Rev. Genet. 9(6), 465-476 (2008).

90 Martinowich K, Hattori D, Wu H et al. DNA methylationrelated chromatin remodeling in activity-dependent $B D N F$ gene regulation. Science (80) 302(5646), 890-893 (2003).

91 Chen WG, Chang Q, Lin Y et al. Derepression of BDNF transcription involves calcium-dependent phosphorylation of MeCP2. Science 302(5646), 885-889 (2003).

92 Chen WV, Alvarez FJ, Lefebvre JL et al. Functional significance of isoform diversification in the protocadherin gamma gene cluster. Neuron 75(3), 402-409 (2012).

93 Kawaguchi M, Toyama T, Kaneko R, Hirayama T, Kawamura Y, Yagi T. Relationship between DNA methylation states and transcription of individual isoforms encoded by the protocadherin- $\alpha$ gene cluster. J. Biol. Chem. 283, 1064-1075 (2008).

94 Bartolomei MS, Ferguson-Smith AC. Mammalian genomic imprinting. Cold Spring Harb. Perspect. Biol. 3(7), 1-17 (2011).

95 Charalambous M, Ferron SR, da Rocha ST et al. Imprinted gene dosage is critical for the transition to independent life. Cell Metab. 15, 209-221 (2012).

96 Bourc'his D, Xu GL, Lin CS et al. Dnmt3L and the establishment of maternal genomic imprints. Science 294(5551), 2536-2539 (2001).

97 Hata K, Okano M, Lei H et al. Dnmt3L cooperates with the Dnmt3 family of de novo DNA methyltransferases to establish maternal imprints in mice. Development 129(8), 1983-1993 (2002).

98 Reik W, Walter J. Genomic imprinting: parental influence on the genome. Nat. Rev. Genet. 2(1), 21-32 (2001).

99 Edwards CA, Ferguson-Smith AC. Mechanisms regulating imprinted genes in clusters. Curr. Opin. Cell Biol. 19(3), 281-289 (2007).

100 Tucker KL, Beard C, Dausman J et al. Germ-line passage is required for establishment of methylation and expression patterns of imprinted but not of nonimprinted genes. Genes Dev. 10(8), 1008-1020 (1996).

101 Cooper WN, Khulan B, Owens S et al. DNA methylation profiling at imprinted loci after periconceptional micronutrient 
supplementation in humans: results of a pilot randomized controlled trial. FASEB J. 26(5), 1782-1790 (2012).

102 Tobi EW, Lumey LH, Talens RP et al. DNA methylation differences after exposure to prenatal famine are common and timing- and sex-specific. Hum. Mol. Genet. 18(21), 4046-4053 (2009).

103 Keverne EB. Genomic imprinting in the brain. Curr. Opin. Neurobiol. 7(4), 463-468 (1997).

104 Horsthemke B, Buiting K. Imprinting defects on human chromosome 15. Cytogenet. Genome Res. 113(1-4), 292-299 (2006).

105 Relkovic D, Doe CM, Humby T et al. Behavioural and cognitive abnormalities in an imprinting centre deletion mouse model for Prader-Willi syndrome. Eur. J. Neurosci. 31(1), 156-164 (2010).

106 Hirasawa R, Feil R. Genomic imprinting and human disease. Essays Biochem. 48, 187-200 (2010).

107 Goto K, Numata M, Komura JI, Ono T, Bestor TH, Kondo $\mathrm{H}$. Expression of DNA methyltransferase gene in mature and immature neurons as well as proliferating cells in mice. Differentiation 56, 39-44 (1994).

108 Fan G, Beard C, Chen RZ et al. DNA hypomethylation perturbs the function and survival of CNS neurons in postnatal animals. J. Neurosci. 21(3), 788-797 (2001).

109 Lucas A. Programming by early nutrition: an experimental approach. J. Nutr. 128(Suppl. 2), S401-S406 (1998).

110 Sinclair KD, Allegrucci C, Singh R et al. DNA methylation, insulin resistance, and blood pressure in offspring determined by maternal periconceptional B vitamin and methionine status. Proc. Natl Acad. Sci. USA 104(49), 19351-19356 (2007).

111 Zeisel SH. Epigenetic mechanisms for nutrition determinants of later health outcomes. Am. J. Clin. Nutr. 89(5), 1488-1493 (2009).

112 Guéant JL, Namour F, Guéant-Rodriguez RM et al. Folate and fetal programming: a play in epigenomics? Trends Endocrinol. Metab. 24(6), 279-289 (2013).

113 Kelsey G. Epigenetics and the brain: transcriptome sequencing reveals new depths to genomic imprinting. Bioessays 33(5), 362-367 (2011).

114 Meaney MJ, Ferguson-Smith AC. Epigenetic regulation of the neural transcriptome: the meaning of the marks. Nat. Neurosci. 13(11), 1313-1318 (2010).

115 Feng J, Fouse S, Fan G. Epigenetic regulation of neural gene expression and neuronal function. Pediatr. Res. 61(Part 2 Suppl. 5), 58-63 (2007).

116 Lefebvre JL, Zhang Y, Meister M et al. gammaProtocadherins regulate neuronal survival but are dispensable for circuit formation in retina. Development 135(24), 4141-4151 (2008)

117 Esumi S, Kakazu N, Taguchi Y et al. Monoallelic yet combinatorial expression of variable exons of the protocadherin-alpha gene cluster in single neurons. Nat. Genet. 37(2), 171-176 (2005).

118 Glusman G, Yanai I, Rubin I et al. The complete human olfactory subgenome. Genome Res. 11(5), 685-702 (2001).
119 Colquitt B, Markenscoff-Papadimitriou E, Duffié R et al. Dnmt3a regulates global gene expression in olfactory sensory neurons and enables odorant-induced transcription. Neuron 83(4), 823-838 (2014).

120 Nugent BM, Wright CL, Shetty AC et al. Brain feminization requires active repression of masculinization via DNA methylation. Nat. Neurosci. 18(5), 690-697 (2015).

121 Guo JU, Su Y, Shin JH et al. Distribution, recognition and regulation of non-CpG methylation in the adult mammalian brain. Nat. Neurosci. 17(2), 215-222 (2014).

122 Schneider E, El Hajj N, Richter S et al. Widespread differences in cortex DNA methylation of the "language gene" CNTNAP2 between humans and chimpanzees. Epigenetics 9(4), 533-545 (2014).

123 Rochtus A, Izzi B, Vangeel E et al. DNA methylation analysis of Homeobox genes implicates $H O X B 7$ hypomethylation as risk factor for neural tube defects. Epigenetics 10(1), 37-41 (2015).

124 Stolk L, Bouwland-Both MI, Van Mill NH et al. Epigenetic profiles in children with a neural tube defect; a case-control study in two populations. PLoS ONE 8(11), 1-8 (2013).

125 Jiang YH, Sahoo T, Michaelis RC et al. A mixed epigenetic/ genetic model for oligogenic inheritance of autism with a limited role for UBE3A. Am. J. Med. Genet. 131, 1-10 (2004).

126 Sahoo T, del Gaudio D, German JR et al. Prader-Willi phenotype caused by paternal deficiency for the HBII-85 C/D box small nucleolar RNA cluster. Nat. Genet. 40(6), 719-721 (2008).

127 Amir RE, Van den Veyver IB, Wan M et al. Rett syndrome is caused by mutations in X-linked MECP2, encoding methyl-CpG-binding protein 2. Nat. Genet. 23(2), 185-188 (1999).

128 Nguyen A, Rauch TA, Pfeifer GP et al. Global methylation profiling of lymphoblastoid cell lines reveals epigenetic contributions to autism spectrum disorders and a novel autism candidate gene, RORA, whose protein product is reduced in autistic brain. FASEB J. 24, 3036-3051 (2010).

129 Zhu L, Wang X, Li X-L et al. Epigenetic dysregulation of SHANK3 in brain tissues from individuals with autism spectrum disorders. Hum. Mol. Genet. 23(6), 1563-1578 (2014).

130 Zhubi A, Chen Y, Dong E, Cook EH, Guidotti a, Grayson DR. Increased binding of MeCP2 to the GAD1 and RELN promoters may be mediated by an enrichment of $5-\mathrm{hmC}$ in autism spectrum disorder (ASD) cerebellum. Transl. Psychiatry 4(1), e349 (2014).

131 Nagarajan RP, Hogart AR, Gwye Y, Martin MR, LaSalle $\mathrm{JM}$. Reduced MeCP2 expression is frequent in autism frontal cortex and correlates with aberrant MECP2 promoter methylation. Epigenetics 1(4), 37-41 (2006).

132 James SJ, Shpyleva S, Melnyk S et al. Complex epigenetic regulation of engrailed-2 (EN-2) homeobox gene in the autism cerebellum. Transl. Psychiatry 3, e232 (2013).

133 Gregory SG, Connelly JJ, Towers AJ et al. Genomic and epigenetic evidence for oxytocin receptor deficiency in autism. BMC Med. 7, 62 (2009). 
134 McConkie-Rosell, , Lachiewicz M, Spiridigliozzi G et al. Evidence that methylation of the FMR-I locus is responsible for variable phenotypic expression of the fragile $\mathrm{X}$ syndrome. Am. J. Hum. Genet. 53(4), 800-809 (1993).

135 Gu Y, Shen Y, Gibbs RA, Nelson DL. Identification of FMR2, a novel gene associated with the FRAXE CCG repeat and CpG island. Nat. Genet. 13(1), 109-113 (1996).

136 Novakovic B, Saffery R. The ever growing complexity of placental epigenetics - role in adverse pregnancy outcomes and fetal programming. Placenta 33(12), 959-970 (2012).

137 Genomics England. www.genomicsengland.co.uk

138 Avon Longitudinal Study of Parents and Children. www.bristol.ac.uk/alspac

139 Bibikova M, Barnes B, Tsan C et al. High density DNA methylation array with single $\mathrm{CpG}$ site resolution. Genomics 98(4), 288-295 (2011).
140 Horvath S. DNA methylation age of human tissues and cell types. Genome Biol. 14(10), R115 (2013).

141 Houseman EA, Molitor J, Marsit CJ. Reference-free cell mixture adjustments in analysis of DNA methylation data. Bioinformatics 30(10), 1431-1439 (2014).

142 Nazor KL, Boland MJ, Bibikova M et al. Application of a low cost array-based technique - TAB-Array - for quantifying and mapping both $5 \mathrm{mC}$ and $5 \mathrm{hmC}$ at single base resolution in human pluripotent stem cells. Genomics 104(5), 358-367 (2014).

143 McNulty B, McNulty H, Marshall B et al. Impact of continuing folic acid after the first trimester of pregnancy: findings of a randomized trial of Folic Acid Supplementation in the Second and Third Trimesters. Am. J. Clin. Nutr. 98(1), 92-98 (2013). 